\title{
JOGO BONITO OU FEIO: O QUE É E COMO PODEMOS QUANTIFICAR?.
}

\section{Letícia P. Montoya*, Julia B. Augusto, Luciano A. Mercadante.}

\section{Resumo}

O objetivo desse estudo foi analisar quais indicadores quantitativos de uma partida de futebol podem estar relacionados às classificações de jogos feios e bonitos. Utilizamos o método misto do tipo sequencial exploratório, caracterizado por uma primeira etapa quantitativa seguida por uma etapa qualitativa. Na etapa quantitativa levantamos os indicadores de desempenho de todas as partidas da Copa do Mundo 2018 disponíveis no website oficial da FIFA e selecionamos quatro jogos com características distintas. Na etapa qualitativa, os jogos selecionados foram assistidos e classificados entre jogo bonito ou feio por dez voluntários do estudo a partir de um questionário aberto. Verificamos que jogo bonito está associado ao número de finalizações ao gol, a competitividade durante a partida, ao número de passes certos e à quantidade de gols no jogo.

\section{Palavras-chave:}

Futebol, Estética e Indicadores de Desempenho.

\section{Introdução}

Durante a Copa do Mundo de futebol é comum que os torcedores se reúnam para assistir juntos às partidas das seleções nacionais, e QUESTÕES RELACIONADAS ÀS PROPRIEDADES E JULGAMENTOS ESTÉTICOS dos jogos sejam evocadas (BORGE; SMITH; BRUUN VAAGE, 2015). Os conceitos de BONITO E FEIO são frequentemente utilizados nessas classificações, além de ser encontrado com frequência o uso dessas expressões ao fazer referências às partidas de futebol na literatura (CONN, 2010; DUBAL, 2010; HALLINAN; HUGHSON, 2009). E apesar da grande popularidade das expressões, as definições ainda são desconhecidas de modo a apresentar um potencial para serem exploradas cientificamente. Dessa forma, o presente estudo pretende investigar quais indicadores quantitativos de uma partida de futebol são relacionados às classificações de jogo bonito ou feio.

\section{Métodos}

Figura 1. Etapas da pesquisa

\begin{tabular}{|c|}
\hline DETALHES DA FASE \\
\hline $\begin{array}{l}\text { Coleta dos dados } \\
\text { quantitativos, } \\
\text { disponiveis no site } \\
\text { da FIFA }\end{array}$ \\
\hline $\begin{array}{l}\text { Análises dos dados } \\
\text { quantitativos por } \\
\text { jogo }\end{array}$ \\
\hline $\begin{array}{l}\text { Seleção dos } 4 \\
\text { jogos com } \\
\text { características } \\
\text { bem distintas }\end{array}$ \\
\hline $\begin{array}{c}\text { Jogos assistidos } \\
\text { pelos } \\
\text { pesquisadores }\end{array}$ \\
\hline $\begin{array}{c}\text { Elaboração do } \\
\text { questionário }\end{array}$ \\
\hline
\end{tabular}

\section{DETALHES DA FASE 2}

\begin{tabular}{|c|}
\hline \multicolumn{1}{|c|}{ Transmissão dos } \\
jogos para os \\
voluntários do \\
estudo com o \\
questionário \\
\hline \multicolumn{2}{|c|}{ Classificação } \\
entre jogo bonito \\
ou feio pelos \\
voluntários do \\
estudo através do \\
questionário \\
\hline \multicolumn{2}{|c|}{ Confronto dos } \\
dados da fase 1 \\
com os da fase 2, \\
podendo identificar \\
quais indicadores \\
quantitativos foram \\
mais percebidos \\
pelos voluntários \\
durante os jogos
\end{tabular}

\section{Resultados}

Tabela 1. Resultados dos questionários

\begin{tabular}{|c|c|c|c|}
\hline $\begin{array}{c}\text { JOGO } 1 \\
\text { SÉRVIA } 1 \text { X } 2 \text { SUIÇA } \\
\text { Variável de interesse: } \\
\text { COMPETITIVIDADE }\end{array}$ & $\begin{array}{c}\text { JOGO } 2 \\
\text { COREIA } 2 \text { X } 0 \text { ALEMANHA } \\
\text { Variável de interesse: } \\
\text { POSSE E FINALIZAÇŌES }\end{array}$ & $\begin{array}{c}\text { JOGO } 3 \\
\text { BĖLGICA } 5 \text { X } 2 \text { TUNISIA } \\
\text { Variável de interesse: } \\
\text { GRANDE NUMEROS DE } \\
\text { GOLS }\end{array}$ & $\begin{array}{c}\text { JOGO } 4 \\
\text { IRÄ 0 X 1 ESPANHA } \\
\text { Variável de interesse: } \\
\text { MUITAS FINALIZAÇÖES }\end{array}$ \\
\hline $\begin{array}{l}\text { Participante 1: "Jogo bonito; } \\
\text { Quantidade de chances } \\
\text { claras de gols; Número de } \\
\text { gols em uma partida; Decisão } \\
\text { do resultado da partida } \\
\text { acontecer nos últimos } \\
\text { minutos." }\end{array}$ & $\begin{array}{c}\text { Participante 1: "Jogo feio; } \\
\text { Poucas chances reais de } \\
\text { gols; Apenas um dos times } \\
\text { se propõe a manter a posse } \\
\text { de bola." }\end{array}$ & $\begin{array}{l}\text { Participante 2: "Jogo bonito; } \\
\text { Jogo com elevado números } \\
\text { de gols; Jogo entrelinhas } \\
\text { realizado pela Bélgica." }\end{array}$ & $\begin{array}{l}\text { Participante 3: "Jogo feio; } \\
\text { Muitos chutões/ataques } \\
\text { desperdiçados; Domínio da } \\
\text { Espanha sem resultados em } \\
\text { gols e efetividade de } \\
\text { chutões." }\end{array}$ \\
\hline $\begin{array}{l}\text { Participante 2: "Jogo bonito; } \\
\text { Jogo ofensivo rápido e busca } \\
\text { de profundidade; } \\
\text { Finalizaçōes de média } \\
\text { distância; Agressividade na } \\
\text { marcação (pressão ao } \\
\text { portador da bola)." }\end{array}$ & $\begin{array}{c}\text { Participante 4: "Jogo feio; A } \\
\text { dificuldade de criar chances } \\
\text { claras de gol; A equipe } \\
\text { coreana prendendo muito a } \\
\text { bola no campo ofensivo, } \\
\text { sofrendo muitos desarmes." }\end{array}$ & $\begin{array}{l}\text { Participante 8: "Jogo bonito; } \\
\text { A grande quantidade de gols } \\
\text { feito durante a partida que } \\
\text { não é muito comum de } \\
\text { acontecer." }\end{array}$ & $\begin{array}{l}\text { Participante 7: "Jogo feio; Por } \\
\text { não ter acontecido } \\
\text { muitas jogadas } \\
\text { criadas/chances de gols } \\
\text { claras por parte de ambos os } \\
\text { times, embora a Espanha } \\
\text { tenha dominado o jogo, não } \\
\text { conseguiu finalizar de } \\
\text { maneira efetiva" }\end{array}$ \\
\hline \multirow{2}{*}{$\begin{array}{c}\text { Participante 4: "Jogo bonito; } \\
\text { A quebra da primeira linha de } \\
\text { marcação com passes entre } \\
\text { os marcadores posicionados } \\
\text { no centro do campo; A virada } \\
\text { com gol no final; O belo gol } \\
\text { suíço. }\end{array}$} & $\begin{array}{l}\text { Participante 5: "Jogo feio; } \\
\text { Pouquíssimas chances de } \\
\text { gols; Muitos erros de passe." }\end{array}$ & \multirow{2}{*}{$\begin{array}{l}\text { Participante 9: "Jogo bonito; } \\
\text { Muitas chances de gol; Gols } \\
\text { bonitos, trabalhado com } \\
\text { assistências bonitas; } \\
\text { Quantidade de gols; } \\
\text { Assistências inteligentes." }\end{array}$} & \multirow{2}{*}{$\begin{array}{l}\text { Participante 9: "Não houve } \\
\text { muitas assistências, pouca } \\
\text { competitividade, poucas } \\
\text { chances reais de gol." }\end{array}$} \\
\hline & $\begin{array}{c}\text { Participante 6: "Jogo feio; } \\
\text { Pouquíssimos ataques que } \\
\text { apresenta-se perigo ao } \\
\text { goleiro." }\end{array}$ & & \\
\hline
\end{tabular}

\section{Conclusões}

De modo geral, concluímos que os indicadores de desempenho presentes nas quatro partidas analisadas permitiram caracterizar a estética do jogo. Verificamos que jogo bonito está associado ao número de finalizações ao gol, criando chances claras de gols, a competitividade durante a partida, número de passes certos e de gols no jogo. Já o jogo caracterizado como feio está principalmente relacionado à falta de finalizações ao gol, deixando de criar chances claras de gols, com ataques desperdiçados, assim como a falta de competitividade e o grande número de passes errados.

\section{Agradecimentos}

Agradecimento ao meu orientador Luciano Allegretti Mercadante, a minha co-orientadora Júlia Barreira Augusto e ao Conselho Nacional de Desenvolvimento Científico e tecnológico - CNPq.

BORGE, S.; SMITH, M.; BRUUN VAAGE, M. The Aesthetics of Football. Sport, Ethics and Philosophy, v. 9, n. 2, p. 93-96, 2015.

CONN, D. The Beautiful Game? : Searching for the Soul of Football. [s.l: s.n.].

DUBAL, S. The neoliberalization of football: Rethinking neoliberalism through the commercialization of the beautiful game. International Review for the Sociology of Sport, v. 45, n. 2, p. 123-146, 1 jun. 2010.

HALLINAN, C.; HUGHSON, J. The beautiful game in Howard's 'Brutopia' football, ethnicity and citizenship in Australia. Soccer \& Society, v. 10, n. 1, p. $1-8,3$ jan. 2009. 